\title{
TRAJETÓRIA: FATOS E FOTOS DA PESQUISA PERFIL DA ENFERMAGEM
}

Neyson Pinheiro Freire ${ }^{1}$

APesquisa Perfil da Enfermagem no Brasil foi realizada pela Fundação Oswaldo Cruz (Fiocruz), por iniciativa do Conselho Federal de Enfermagem (Cofen), e contou com a participação de pesquisadores da Escola Nacional de Saúde Pública Sérgio Arouca (ESNP) e um grande número de colaboradores de instituições científicas do país. Teve como objetivo analisar e traçar o perfil da equipe de enfermagem, dos enfermeiros e dos auxiliares e técnicos de enfermagem, de forma a conhecer a sua dinâmica, considerando as condições de trabalho, emprego e formação, desde seus aspectos econômicos, sociais, até os aspectos éticos e políticos que envolvem as práticas dos profissionais de enfermagem.

A pesquisa, realizada em aproximadamente $50 \%$ dos municipios brasileiros e em todos os 27 estados da Federação, inclui desde profissionais no começo da carreira (auxiliares e técnicos, que iniciam com 18 anos; e enfermeiros, com 22) até os aposentados (pessoas de até 80 anos). 0 estudo ouviu 35.916 mil profissionais em todo o Brasil, com uma amostra entre profissionais selecionados aleatoriamente,dentro de um universo de mais de 1,8 milhão de trabalhadores.

O Perfil da Enfermagem no Brasil é o mais amplo levantamento sobre uma categoria profissional já realizado na América Latina. Foi a primeira pesquisa a oferecer um panorama nacional sobre a situação dos trabalhadores da Enfermagem no Brasil.

O INÍCIO DA PESQUISA - O Cofen, a fim de retratar a realidade da categoria, com a abordagem de toda a comunidade profissional e fornecer importantes subsídios para a discussão do trabalho em saúde, iniciou, em 2009. a construção do projeto de pesquisa da enfermagem no Brasil. A proposta inicial foi de que a pesquisa, seria realizada de forma colaborativa pela Fiocruz, com a parceria do Ministério da Saúde, da Associação Brasileira de Enfermagem - ABEn, da Federação Nacional de Enfermagem - FNE, da Confederação Nacional dos Trabalhadores na Saúde - CNTS, da Confederação Nacional dos Trabalhadores em Seguridade Social - CNTSS e da Associação Nacional de Auxiliares e Técnicos de Enfermagem - ANATEN, no sentido de oferecer o retrato atual da enfermagem, buscando conhecer e analisar o perfil das categorias de enfermagem.

Após sucessivas reuniões com as entidades envolvidas, foi possivel construir o Projeto de Pesquisa e o questionário de coleta de dados. O projeto foi aprovado pelo Comité de Ética e Pesquisa (CEP) da ESNP/Fiocruz. Em 26 de julho de 2011, o presidente do Cofen à época, enfermeiro Manoel Neri, assinou o convênio com a Fiocruz para realização da Pesquisa.

Em meados de 2012, após amplo processo de divulgação na imprensa nacional e regional, iniciou-se de fato a aplicação dos questionários. A pesquisa de campo se encerrou em setembro de 2013 , tendo como resultado um extenso banco de dados.

Em 6 de maio de 2015, em um evento realizado pelo Cofen em Brasilia, com a participação de mais de 300 pessoas e cobertura da imprensa nacional, aconteceu o lançamento oficial dos resultados da pesquisa Perfil da Enfermagem no Brasil. A pesquisa teve, ainda, lançamento de dados estaduais em todos as unidades da federação. A apresentação dos resultados foi seguida de debate e entrevistas à imprensa, ampliando a compreensão sobre a realidade local e subsidiando discussões de políticas públicas.

POLÍTICAS PÚBLICAS - Os resultados gerados pela pesquisa Perfil da Enfermagem no Brasil comprovaram forte desgaste profissional, baixos salários e indícios de saturação do mercado de trabalho. Os dados subsidiaram a discussão de políticas públicas e intervenções para a melhoria da assistência em Enfermagem, especialmente quanto às condições de vida e trabalho dos profissionais.

Dois projetos de lei elaborados pelo Cofen à luz dos dados relevados pela pesquisa já tramitam no Congresso Nacional. O PL 2891/2015, apresentado pelo deputado Orlando Silva (PCdoB/SP), proíbe a graduação de enfermeiros e a formação à distância de técnicos e auxiliares de Enfermagem. O PLS597/2015, apresentado pelo senador Valdir Raupp (PMDB/RO), aborda outro ponto crítico, a ausência de locais adequados para o descanso legalmente assegurado aos profissionais plantonistas. 


\section{SAIU NA MÍDIA}

Com um diagnóstico detalhado da situação da profissão em todo o país, a pesquisa Perfil da Enfermagem repercutiu nacionalmente e na midia regional.

No Correio Braziliense, a pesquisa deu origem a um caderno especial.

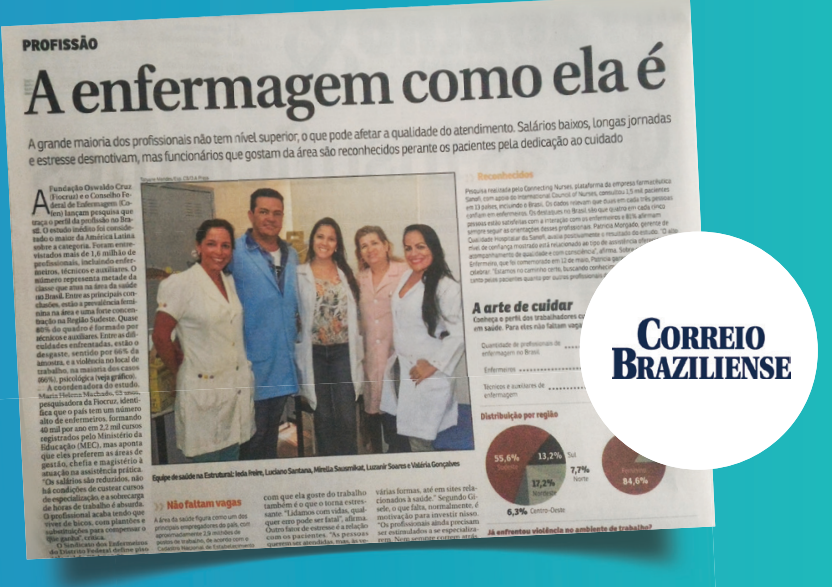

A Folha de São Paulo relatou insegurança da equipe nas unidades de Saúde, com agressões verbais e até físicas.

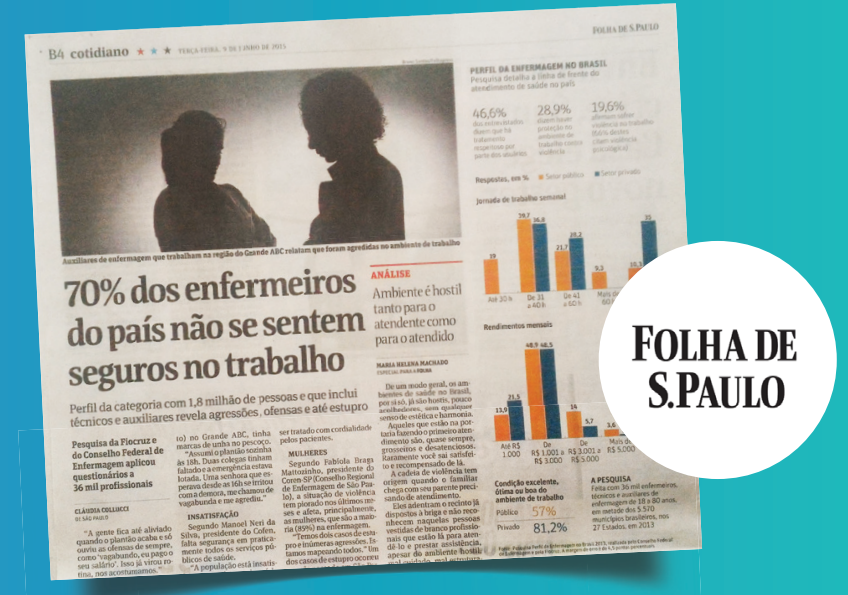

O Jornal O Dia destacou o percentual de profissionais que sofrem desgaste.

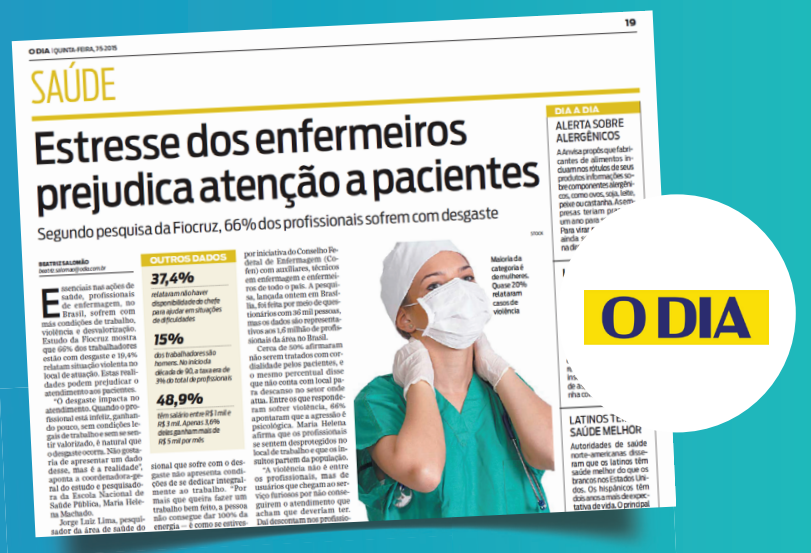

Na TV, o Perfil da Enfermagem foi tema de reportagem na Record, SBT, Band, Globo nacional, e afiliadas locais nos Estados onde ocorreu o lançamento da pesquisa, além da GloboNews, TV Senado e no Canal Saúde. A repercussão nas rádios foi inédita, 369 emissoras difundiram os dados da pesquisa país afora, com destaque para as rádios Joven Pan, CNB e Globo. As matérias foram produzidas com apoio da Assessoria de comunicação do Cofen, Conselhos Regionais e Fiocruz.

A OPINIÃO DOS GESTORES DO SUS, FIOCRUZ E COFEN

\section{MINISTÉRIO DA SAÚDE}

"A pesquisa Perfil da Enfermagem no Brasil realizada pela Fundação Oswaldo Cruz (FIOCRUZ), poriniciativa do Conselho Federal de Enfermagem (COFEN) é um importante instrumento para os gestores públicos pensarem políticas públicas para toda a força de trabalho em saúde e as representações de trabalhadores atualizarem suas pautas. Evidências como a grande concentração de trabalhadores de nivel médio; grande concentração de profissionais na região Sudeste e capitais e aumento do desemprego no setor; são desafios que temos que enfrentar."

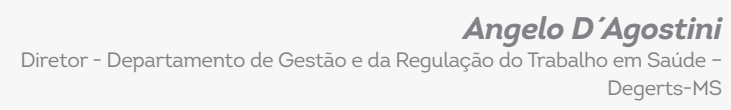

“A regulação das profissões em saúde é uma responsabilidade estatal que tem como objetivo garantir à população o acesso universal, igualitário e integral aos serviços de saúde e condições aos trabalhadores para desenvolver suas atribuições. A Pesquisa Perfil da Enfermagem do Brasil como uma parceria entre Conselho Profissional, área educacional e de pesquisa e órgãos governamentais propicia avançarmos para a unificação das ações no processo de regulação profissional".

Hêider Aurélio Pinto Secretário - Secretaria de Gestão do Trabalho e da Educação na Saúde - 


\section{CONSELHO NACIONAL DE SECRETÁRIOS DE SAÚDE (CONASS)}

\section{A Releuância da Pesquisa Perfil da Enfermagem no Brasil}

"O Sistema Único de Saúde (SUS), desde sua instituição em 1998, tornou-se o principal mercado de trabalho dos profissionais da saúde, tendo aumentado de forma significativa os postos de trabalho das profissões da área da enfermagem, tanto na rede pública (especialmente nos municipios) quanto da rede privada contratada.

Este crescimento impulsionou o aumento dos cursos de graduação em enfermagem e do número de vagas nos cursos existentes da ordem de $1.100 \%$, na esfera privada e de $132 \%$ na esfera pública, aumentando a facilidade de acesso à formação superior.

Essa expansão, aliada à gestão do trabalho como um todo, inclui a necessidade de repensar o planejamento dos recursos humanos disponiveis para o trabalho no SUS e propõe uma nova agenda para os gestores da saúde.

A Pesquisa Perfil da Enfermagem no Brasil realizada pela FIOCRUZ, por meio do Núcleo de Estudos e Pesquisas em Recursos Humanos em Saúde da Escola Nacional de Saúde Pública Sergio Arouca (NERHUS/ENSP/FIOCRUZ) tem como principal objetivo conhecer a situação atual da enfermagem no país, no recente contexto socioeconômico e político brasileiro, e possibilita aos gestores do SUS acesso a informações atualizadas acerca desta importante categoria profissional, contribuindo assim, para a qualificação do trabalho e do trabalhador e consequente melhoria da qualidade da atenção prestada ao cidadão".

João dos Reis Gabardo Presidente do Conass

\section{CONSELHO NACIONAL DE SECRETARIAS MUNICIPAIS DE SAÚDE (CONASEMS)}

“O CONASEMS felicita a iniciativa do Conselho Federal de Enfermagem (Cofen), em parceria com a Fundação Oswaldo Cruz (Fiocruz), na realização da pesquisa "Perfil da Enfermagem", o SUS carece de pesquisas como essa, que nos possibilitam conhecer recortes de sua força de trabalho.

Sendo o SUS um sistema descentralizado e gerido de forma compartilhada e pactuada entre as três esferas de gestão - entes federados e autônomos - mapear e identificar efetivamente a força de trabalho desse sistema é um desafio enorme e complexo, e mais do que nunca extremamente necessário.

Para o gestor fazer um planejamento nem sempre apoiado em bases e evidências cientificas de necessidades do sistema, quantidade e capacidade de resposta de sua força de trabalho para o adequado dimensionamento, tem sido uma prática de muito desgaste e sofrimento, tanto aos gestores quanto aos trabalhadores do SUS.

Essa pesquisa corrobora e não deixa dúvidas acerca do que, nós gestores municipais já sabiamos - a enfermagem é a força motriz do SUS, com seu 1,8 milhão de trabalhadores - 50\% do total de trabalhadores do SUS - desses, 38,8\% no setor público municipal construindo, tocando e defendendo diariamente em cada recanto desse país, o nosso SUS.

Desde a Constituição Federal de 1988, seguida pela Lei Orgânica do SUS - Lei 8080/90 - o CONASEMS vem atuando fortemente em todas as frentes para a efetiva implantação do SUS, defendendo todos os seus principios e diretrizes. Vimos convergir grandes esforços no sentido de regionalizar e descentralizar os serviços de saúde, o que revelou a necessidade de ampliar as capacidades e organizar a base do sistema, que passou a ter centralidade no município. Esse expressivo aumento na responsabilidade pela contratação e capacitação da força de trabalho em saúde atribuida aos municipios não ocorreu no contexto de uma política de Estado que adequasse o pacto federativo brasileiro, criando condições mais favoráveis para que a esfera municipal assumisse as novas responsabilidades. Rever isso é nossa luta sempre em pauta.

Sendo assim, pesquisas como essa são imprescindiveis no sentido de apoiar com evidências científicas o SUS, e aqui destacamos as gestões municipais, no planejamento e organização da gestão do trabalho e elaboração de planos de cargos, carreiras e salários que orientem e valorizem os trabalhadores do SUS no município".

Mauro Guimarães Junqueira 


\section{FUNDAÇÃO OSWALDO CRUZ (FIOCRUZ)}

"Atividade historicamente associada à caridade cristã, a enfermagem transforma-se em profissão secular no inicio do século XIX, sem, contudo, desvencilhar-se de mitos, a exemplo do ideal de abnegação, que, como se sabe, ainda persistem no imaginário sobre um conjunto de profissionais, cujo trabalho é essencial em todos os sistemas de saúde e requer, portanto, valorização compativel por parte da sociedade.

Nada melhor do que boas pesquisas para lidar com idealizações que não se sustentam na experiência cotidiana desses profissionais. E, no caso do Brasil, ainda que estudos monográficos sobre os conhecimentos e as práticas de enfermagem venham se desenvolvendo de forma crescente, fazia falta uma pesquisa abrangente sobre as características e as condições de exercicio da profissão. Esta lacuna foi preenchida com a publicação dos resultados de Perfil da Enfermagem no Brasil, pela Escola Nacional de Saúde Pública/Fundação Oswaldo Cruz, em resposta à iniciativa do Conselho Federal de Enfermagem (COFEN). Coordenada pela socióloga Maria Helena Machado, a pesquisa integra uma linha orientada pelos pressupostos da sociologia das profissões, da qual vem resultando importantes estudos sobre o universo do trabalho em saúde, em particular sobre a profissão médica. Em um momento em que se busca favorecer a formação e a prática de equipes multiprofissionais, é mais do que bem vinda esta verdadeira cartografia do exercicio da enfermagem no país.

Um primeiro dado relevante é a representatividade estatística dos profissionais em questão - enfermeiros, técnicos e auxiliares - uma vez que eles reúnem aproximadamente 1,8 mil trabalhadores, cerca da metade dos que atuam no setor saúde no pais. Trata-se ainda de um segmento predominantemente feminino (85\%), ainda que se verifique 0 progressivo aumento do número de homens. A abordagem de problemas relacionados à categoria gênero em sua interface com o trabalho permanece como um dos mais instigantes objetos de pesquisa sociológica e, provavelmente, novas propostas de estudo sobre esta relação serão estimuladas pela presente publicação.

Com a pesquisa, sabemos um pouco mais sobre este universo tão significativo de profissionais. Do mesmo modo que os médicos, eles se concentram na região Sudeste e nas capitais, constatação que implica pensar em novas possibilidades de políticas públicas voltadas para o provimento de profissionais de saúde, tal como vêm ocorrendo na implementação do Programa Mais Médicos. Em contraste com esses profissionais, os da enfermagem encontramse, no entanto, em situação próxima ao desemprego.

Aprendemos também que os profissionais de enfermagem procuram aperfeiçoar sua formação, contudo ainda são restritas as opções em modalidades como a Residência em Enfermagem ou a Residência Multiprofissional, e ainda, a mesma lacuna pode ser apontada na formação pós-técnica, todas de grande interesse para o SUS. Ao lado de dados positivos, como os relacionados aos niveis de escolaridade, que contrariam as idéias generalizadas no senso comum sobre um baixo nivel de formação, constatam-se o subsalariamento e as extenuantes jornadas de trabalho. Mais uma vez é de se esperar que os contundentes dados revelados pelo estudo possam ser considerados na definição de políticas coerentes com os princípios do Sistema Único de Saúde, que requerem, não é demais lembrar, a valorização permanente de seus trabalhadores."

Nisia Trindade Lima Vice-Presidente de Ensino, Informação e Comunicação

\section{CONSELHO FEDERAL DE ENFERMAGEM (COFEN)}

"Estar à frente do Conselho Federal de Enfermagem, a entidade que congrega o maior contingente de profissionais de saúde do Brasil, exige tomadas de decisões estratégicas. A pesquisa Perfil da Enfermagem no Brasil foi, sem dúvida, uma decisão arrojada e estratégica que assumimos. Em parceria com a FIOCRUZ, o COFEN pode obter dados, resultados e análises técnico-cientificas de alta relevância pública que permitem construir políticas públicas e tomar medidas específicas no campo da Formação, do Trabalho, das Condições de trabalho e da Gestão em prol de mais de 1,8 milhão de trabalhadoras e trabalhadores da Enfermagem. Nos orgulhamos de oferecer à nossa categoria este valioso e inédito produto científico a todos nós, da Enfermagem!. Um importante instrumento para buscarmos a superação da condição dramática vivenciadas pelos profissionais de Enfermagem no Brasil." 


\section{O POEMA DA PESQUISA}

Após percorrer todos os estados da federação, por ocasião dos lançamentos regionais, o cerimonialista oficial da pesquisa apresentou uma obra circunstancial e menor de qualquer outro grande autor, não fosse esse grande autor nada menos do que Flávio Liffeman. O poema, tão comprometido com a realidade da enfermagem brasileira, merece, mais do que nunca, ser lido e relido. Privilégio do criador e deleite dos leitores.

\section{PERFIL DA ENFERMAGEM}

Flávio Liffeman ${ }^{3}$

Perfil não é um lugar

nem uma situação definida

Perfil é um retrato construido

com matizes de amostras

colhidas pela ciência da matemática

e comprovação estatística

Calcula, aponta, comprova

Valor, honra e impaciência

pela paciência, cuidado e dedicação

É uma história em construção ponte para crescimento estação para conhecimento

Perfil é caracteristica que expõe realidades

credita qualidades

sistematiza deficiências

desperta a busca, a razão

O Brasil de 27 perfis

revela o perfil real de uma profissão

luta, cresce, padece

chora, respira, fortalece

e oficializa a engrenagem Que move um povo, uma nação

Revela o perfil: ENFERMAGEM, Profissão Coragem! 
FOTOS

LANÇAMENTO NACIONAL

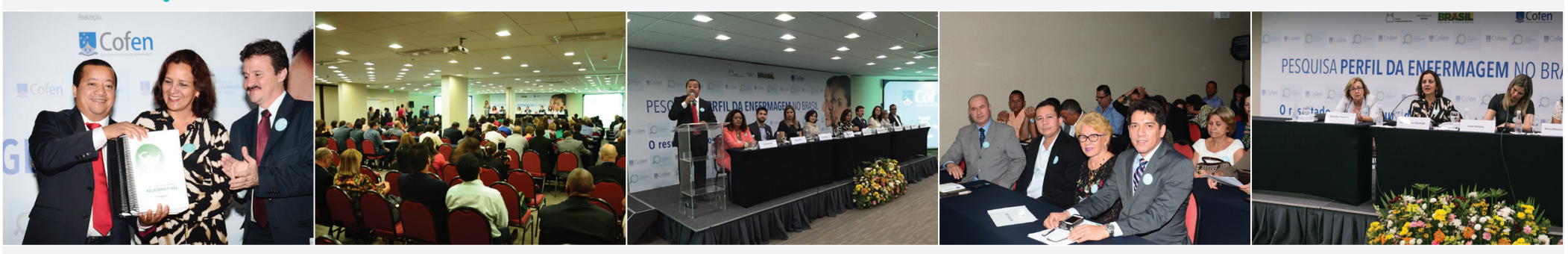

COLETIVA DE IMPRENSA

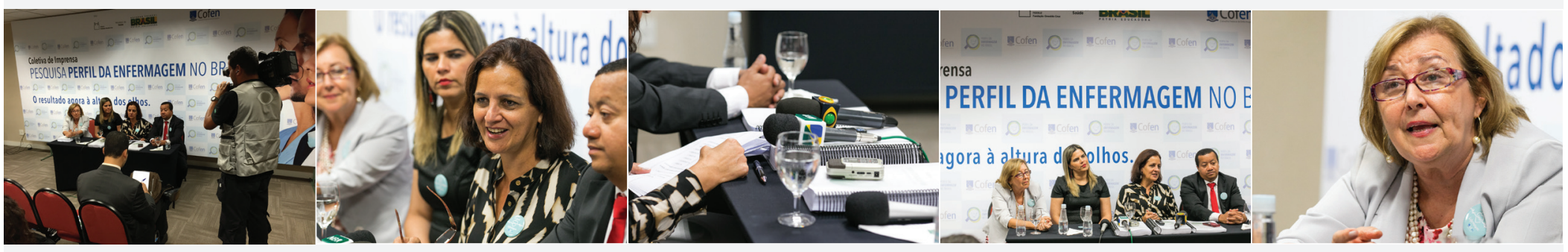

LANCGAMENTOS REGIONAIS

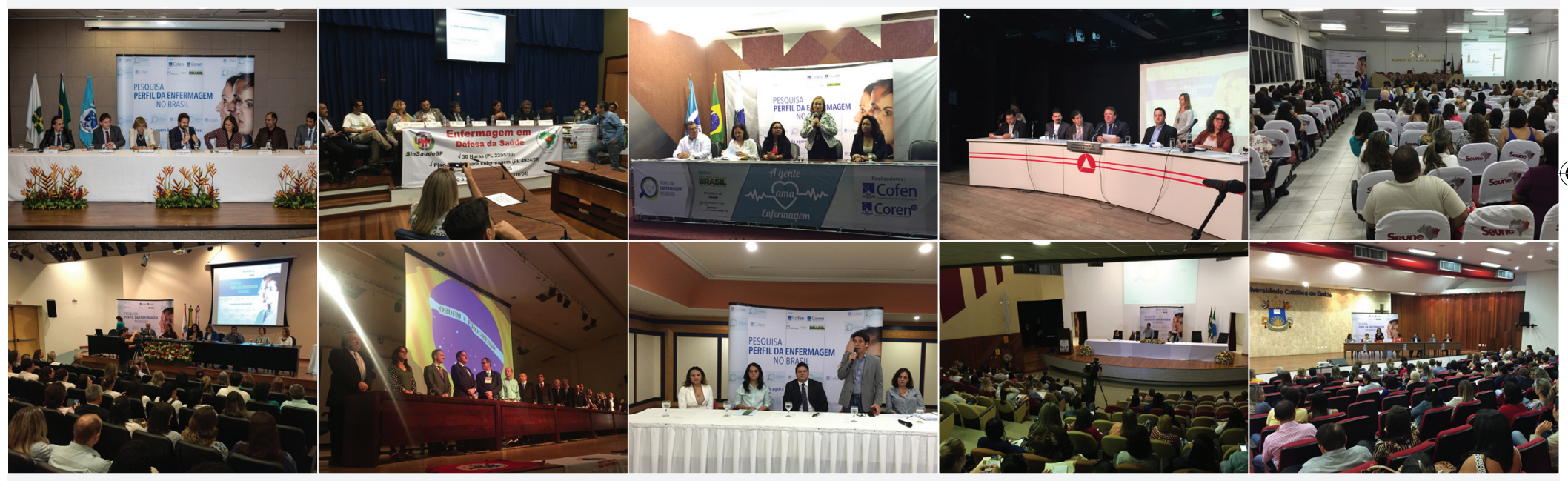

ENTREVISTAS
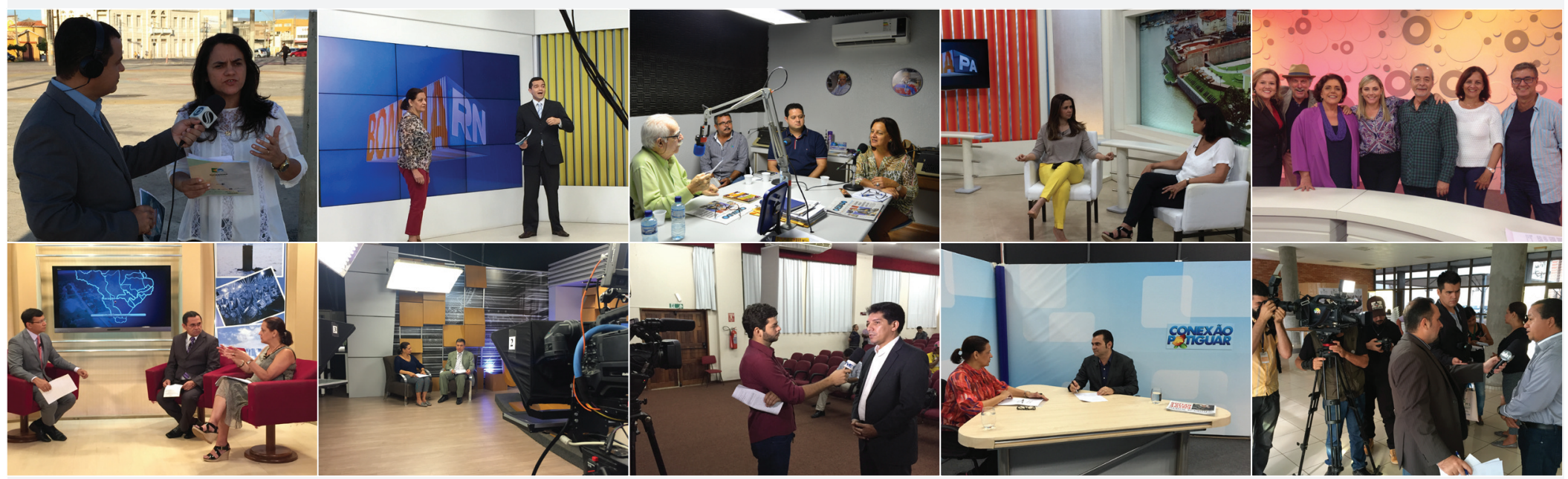


\section{PROCESSO DE SUBMISSÃO}

O processo de submissão é feito somente no endereço: http:// revista.portalcofen.gov.br $\mathrm{O}$ periódico utiliza o sistema de avaliação por pares, preservando o sigilo, com omissão dos nomes de avaliadores e autores. Os artigos submetidos, adequados às normas de publicação, após a pré-análise do Editor Chefe, são enviados aos Editores Associados para seleção de consultores. Finalizada a avaliação dos consultores, o Editor Associado encaminha uma recomendação ao Editor Chefe que decidirá pela aprovação, reformulação ou recusa do artigo.

Podem ser submetidos artigos originais e artigos de revisão.

\section{FORMATO E ESTRUTURA DOS MANUSCRITOS}

\section{Artigos originais}

São manuscritos que apresentam resultados de pesquisa inédita de natureza qualitativa ou quantitativa. São também considerados artigos originais as reflexões teóricas opinativas ou analíticas.

\section{Artigos de revisão}

Estudos de revisão integrativa da literatura, de revisão sistemática com ou sem metanálise.

\section{Identificação do manuscrito}

Título: conciso e informativo;

Autoria: nome(s) do(s) autor(es), indicando a titulação máxima, vínculo institucional e endereço eletrônico do autor correspondente. Os autores devem especificar, em formulário próprio (modelo 1), a participação na elaboração do manuscrito; Idioma: serão aceitos textos em português, espanhol e inglês;

Limite de palavras: o número máximo de palavras é de 3 mil (3.000), incluindo títulos, resumos e descritores nas três línguas (português, inglês e espanhol) e referências;

Formatação: papel A4 (210 x $297 \mathrm{~mm})$, margens de $2,5 \mathrm{~cm}$ em cada um dos lados, letra Times New Roman com corpo 12 , espaçamento duplo e redigido em Word;

Resumo e descritores: o resumo deverá conter de 100 a 150 palavras, incluindo objetivos, metodologia, resultados e conclusões. Os artigos deverão apresentar os resumos em português, inglês e espanhol, sequencialmente na primeira página, incluindo títulos e descritores nos respectivos idiomas.
Os descritores devem ser em número de três a cinco, sendo aceitos somente os vocábulos incluidos na lista de "Descritores em Ciências da Saúde - DeCS-Lilacs", elaborada pela Bireme (acessivel em http://decs.bvs.br), ou no Medical Subject Heading - MeSH (acessivel em www.ncbi.nlm.nih.gov/mesh). Para ensaio clínico, apresentar o número do registro ao final do resumo;

Ilustrações: as ilustrações incluem tabelas, figuras e fotos, inseridas no texto, numeradas, consecutivamente, com algarismos arábicos, na ordem de apresentação. A numeração sequencial é separada para tabelas, figuras e fotos. $O$ título das ilustrações deve ser breve e as notas, quando necessárias, estar após a identificação da fonte. Em caso do uso de fotos, os sujeitos não podem ser identificados sem apresentar permissão, por escrito, para fins de divulgação científica. As ilustrações precisam ser claras para permitir sua reprodução em $8 \mathrm{~cm}$ (largura da coluna do texto) ou $17 \mathrm{~cm}$ (largura da página). Para ilustrações extraídas de outros trabalhos previamente publicados, os autores devem providenciar permissão, por escrito, para a reprodução das mesmas, encaminhando-a na submissão dos manuscritos;

Limitações do estudo: posicionados no final da discussão.

Referências: as referências estão limitadas a 25, apresentadas no formato Vancouver Style (http://www.nlm.nih.gov/bsd/ uniform_requirements.html). É preciso identificar as referências no texto por números arábicos, entre parênteses e sobrescritos. Quando se tratar de citação sequencial, separe os números por traço (ex.: 3-8); quando intercalados, use vírgula (ex.: 1, 4, 12). Na citação dos autores, quando houver mais de um, liste os seis primeiros seguidos de et al., separando-os por vírgula. As citações diretas (transcrição textual) devem estar no corpo do texto, independentemente do número de linhas, e identificadas entre aspas, indicando autor e página(s) (ex.: 1:20-21);

Agradecimentos e Financiamento: posicionados no fim do texto; Aspectos éticos: manuscritos resultantes de pesquisa com seres humanos ou animais, no ato da submissão, deverão vir acompanhados, no sistema on-line, da cópia da aprovação do Comitê de Ética (no caso brasileiro) ou da declaração de respeito às normas internacionais; ${ }^{*}$

Transferência de direitos autorais: os artigos devem ser encaminhados com as autorizações on-line de transferência de direitos à revista (modelo 2). 


\section{UMA PROFISSÃO QUE LIDA COM A VIDA NÃO PODE SER ENSINADA A DISTÂNCIA.}

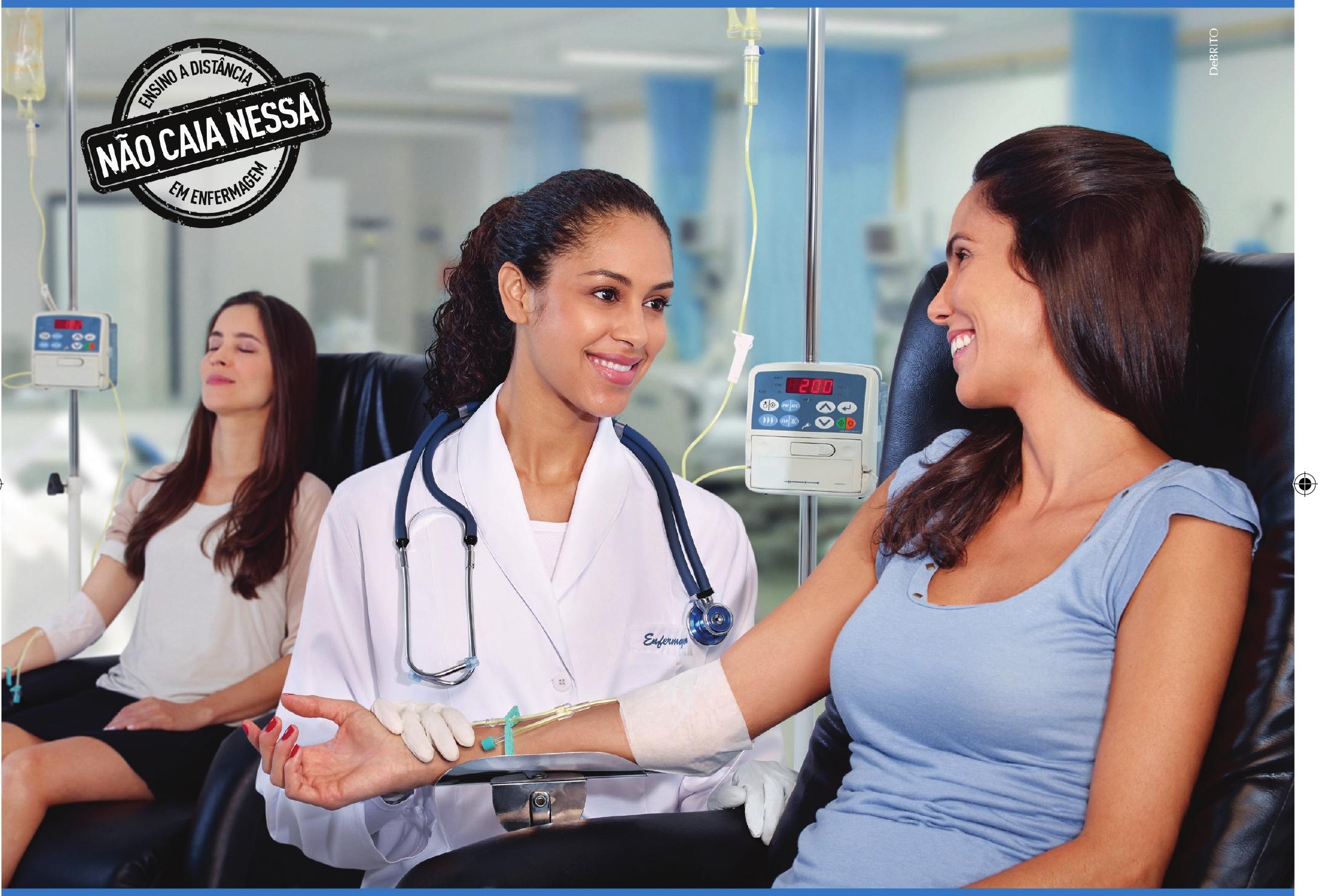

FORMAÇÃO DE ENFERMAGEM, SOMENTE COM ENSINO PRESENCIAL. O Cofen chama a sociedade para fazer parte dessa luta.

Trabalhar com enfermagem exige muito mais do que conhecimento. Exige uma prática que você só desenvolve com aulas presenciais e professores sempre atentos ao seu lado. É por isso que o Cofen apoia todas as iniciativas que buscam aumentar a qualidade dos cursos de enfermagem e valorizar cada vez mais a profissão. A discussão já chegou no Congresso Nacional e a sua opinião pode fazer a diferença.

Esta luta também é sua. Participe em: f//eucurtoaenfermagem

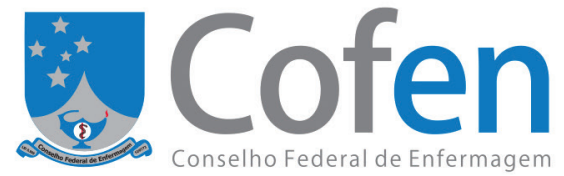

wuw.cofen.govibr 